\title{
Ideias fora do lugar e seus colóquios: insights para a análise das "interpretações do Brasil"
}

\author{
Ideias fora do lugar and its colloquia: \\ insights for analyzing the "interpretations of Brazil"
}

\author{
Sergio B. F. Tavolaro* (i)
}

\begin{abstract}
RESUMO
O presente artigo almeja revisitar Ideias fora do lugar, ensaio seminal de Roberto Schwarz, atento aos diálogos críticos fomentados em sua esteira. Almeja-se explorar o potencial heurístico dessa fatura para lidar com três ordens de problemas que revolvem a produção dos assim chamados intérpretes do Brasil: que aspectos concorreriam para a alegada identidade dessa tradição de pensamento? Em segundo lugar, admitida a enorme diversidade de âncoras explicativas mobilizadas nesse universo intelectual, o que dizer dos critérios e parâmetros ali acionados para descrever e compreender a sociedade brasileira? Por fim, a despeito de seu expresso interesse por fenômenos e problemas pertinentes ao Brasil, que alcance cognitivo poder-se-ia esperar de tais Interpretações? ${ }^{1}$
\end{abstract}

Palavras-chave: Roberto Schwarz; Ideias fora do lugar; Intérpretes do Brasil

\footnotetext{
* Universidade de Brasília, Brasília, DF, Brasil. Professor Associado do Departamento de Sociologia UnB. sergiotavolaro@hotmail.com

${ }^{1} \mathrm{O}$ artigo é fruto do projeto de pesquisa 303189/2019-3. Agradeço às valiosas críticas e sugestões das/os pareceristas anônimas/os da RBS, que me auxiliaram a precisar os argumentos aqui desenvolvidos.
} 


\begin{abstract}
This article aims to revisit Ideias fora do lugar (Ideas out of place), a seminal essay by Roberto Schwarz, attentive to the critiques sparked in its wake. The aim is to explore the heuristic potential of this work to deal with three orders of problems that revolve the production of the so-called "interpreters of Brazil": what aspects would contribute to the alleged identity of this tradition of thought? Secondly, given the enormous diversity of explanatory tools mobilized in this intellectual universe, what about the criteria and parameters used to describe and understand Brazilian society? Finally, despite its express interest in phenomena and problems relevant to Brazil, what cognitive scope could one expect from such interpretations?
\end{abstract}

Keywords: Roberto Schwarz, Ideias for a do lugar, interpreters of Brazil.

Desde sua publicação inaugural, Ideias fora do lugar, ensaio seminal de Roberto Schwarz, não apenas inspirou uma gama notável de trabalhos, como despertou inúmeras polêmicas a propósito das indagações e soluções então balizadas (Arruda, 2019; Rodrigues, 2019). Neste artigo, importa-me revisitar os argumentos centrais do opúsculo, atento a algumas das controvérsias suscitadas acerca das condições de possibilidade (e de impossibilidade) de uma postura ativa do Brasil na cena intelectual moderna. Mas interessame algo mais: ciente da circulação preponderante de Schwarz pela crítica literária e atento às inovações de seu projeto intelectual, almejo explorar o potencial heurístico das interlocuções em torno de Ideias para lidar com três ordens de preocupações que animam o campo de investigação dos assim chamados intérpretes do Brasil:2 (i) que aspectos concorreriam para a alegada identidade dessa tradição de pensamento? (ii) Admitida a enorme diversidade de âncoras explicativas mobilizadas por algumas/uns de suas/ seus mais celebradas/os autoras/es e perspectivas, o que dizer dos critérios e parâmetros ali acionados para descrever e compreender o país? Por fim, (iii)

\footnotetext{
2 A expressão interpretações do Brasil tem sido empregada para denominar um amplo conjunto de pensadoras/es que, ao menos desde a segunda metade do século 19, dedicou-se a compreender os processos de construção da sociedade brasileira, bem como os caminhos que conduziram o país à modernidade. A lista desses personagens é extensa e, de modo algum, definitiva. Veja-se, por exemplo, Um enigma chamado Brasil (Botelho \& Schwarcz, 2009), Pensadores que inventaram o Brasil (Cardoso, 2013) e Interpretations of Brazil, contemporary (de)formations (Lage, 2016).
} 
a despeito de seu expresso interesse por fenômenos pertinentes à sociedade brasileira, que alcance cognitivo poder-se-ia expectar de tais interpretações?3

A conjectura do artigo é que os debates fomentados por e a partir daquele ensaio insinuam um registro promissor para cada um dos problemas supramencionados. Trata-se, com isso, de dizer que tal fatura oferece uma chave de leitura valiosa, capaz de auxiliar-nos a discernir certa "regularidade na vasta dispersão"4 de retratos da vida social brasileira delineados por nossos intérpretes. Em segundo lugar, entendo que essas mesmas discussões nos abrem a possibilidade de correlacionar entre si as distintas variáveis empenhadas com o anseio de decifrar o país, além de nos ajudar a situá-las visà-vis certo imaginário da modernidade. Mas isso não é tudo. Está claro que, em virtude dos objetivos analíticos muitas vezes anunciados - a princípio, respeitantes tão somente à vida nacional -, não raro vemo-nos inclinados a atribuir a esses empreendimentos interpretativos um alcance deveras limitado. Gostaria, no entanto, de avançar uma apreciação alternativa: como pretendo também argumentar, os colóquios em torno de Ideias lançam luz sobre as convergências e desacordos, sobre as afinidades e dissensões entre tais formulações e o próprio discurso sociológico da modernidade.

\section{Ideias fora do lugar: proposições e dissensões}

Talvez reste pouco a acrescentar a propósito das influências que, direta e indiretamente, contribuiriam para a concepção de Ideias. A bem da verdade, o próprio autor tratou de mencionar algumas: além da "inspiração de Marx"5 e do débito inestimável com "Antonio Candido", foram-lhe fundamentais Sartre, "Lukács, Benjamin, Brecht e Adorno" (Schwarz, 1998, p. 13). ${ }^{6}$ Somem-se a estes Fernando H. Cardoso e Maria Sylvia de Carvalho

\footnotetext{
${ }^{3} \mathrm{O}$ teor das questões contempladas pela vasta fortuna crítica de Ideias é indicativo do potencial do ensaio para também lidar com problemas caros ao pensamento social brasileiro. Eis alguns exercícios já realizados nessa direção: Lage (2016), Maia (2009), Ricupero (2008) e Schwarcz (1993).

${ }^{4}$ Para emprestar uma conhecida noção de Arqueologia do Saber.

${ }^{5}$ Considere-se as reflexões do próprio autor sobre a importância em sua trajetória do conhecido grupo de leitura d'O Capital (Schwarz, 1999, p. 104-128). É preciso, todavia, ter em conta suas dissidências frankfurtianas com as motivações prioritárias do Seminário (Schwarz, 1999, p. 126-128), à sua vez alusivas às influências que o "marxismo sombrio" da Escola e a dialética negativa de Adorno exerceram sobre ele (Schwarz, 1999, p. 126).

${ }^{6}$ Apesar de não ser o propósito deste artigo reconstruir as influências intelectuais de Schwarz, mencionarei à frente algumas delas, atento à trinca Candido/Adorno/Sartre.
} 
Franco - esta, pelas formulações a respeito da sociabilidade e do lugar do "homem livre e pobre" na sociedade escravocrata; aquele, pelas reflexões acerca dos nexos entre "escravidão" e "capitalismo" moderno. ${ }^{7}$ Ao lado de Candido, ambos constituiriam peças-chave do "projeto coletivo da dialética" desenvolvido na cena intelectual da USP (Schwarcz \& Botelho, 2008, p. 148149 e demais passagens da entrevista com o próprio autor; Schwarz, 1999, p. 113-118; Arantes, 1992, p. 62-71; Helayel \& Brasil Jr., 2019; Ricupero, 2013). Quanto à “ambiência” dessa instituição, Elide R. Bastos alude justamente ao enquadramento analítico das investigações dedicadas a compreender “as razões, o perfil e os efeitos do atraso no Brasil” (Bastos, 2002, p. 185186): por um lado, "a recusa de uma visão dualista” e "de uma explicação linear” para a formação do país (p. 186); por outro, a percepção aguda da singular coexistência "de elementos arcaicos e modernos na estruturação da sociedade brasileira” (p. 186-187). ${ }^{8}$ Tais aspectos auxiliam-nos, em igual medida, a mensurar a dívida de Schwarz com Caio Prado Jr. e Fernando Novais, bem como a sopesar a presença de Celso Furtado em Ao vencedor as batatas (Arantes, 1992, p. 84-90; Schwarz, 1999, p. 114, p. 116-117; Waizbort, 2002, p. 125, p. 138) - em todos esses casos, em convergência com suas cogitações a respeito de "nossa posição na divisão internacional do trabalho" e das questões ideológicas implicadas na combinação entre "atraso social" e "progresso material” (Schwarz, 1977, p. 80). ${ }^{9}$

\footnotetext{
${ }^{7}$ Como se sabe, a obra de referência de Carvalho Franco foi Homens livres na ordem escravocrata, ao passo que a de Cardoso foi Capitalismo e escravidão no Brasil escravocrata, resultantes de suas respectivas teses de doutorado. Seria interessante também aquilatar o impacto do livro posterior de Cardoso, Empresário industrial e desenvolvimento econômico (Schwarz, 1999, p. 120-124) e de Dependência e desenvolvimento na América Latina (Schwarz, 1999, p. 124125), impacto este que, na avaliação de Franco (1976, p. 63-64), o teria impelido às armadilhas "dualistas" que permeiam nossa vida intelectual. Tendo em conta os objetivos precípuos do presente trabalho, não poderei aprofundar essa questão. De todo modo, mais adiante, recuperarei alguns dos diálogos de Schwarz com Franco. Veja-se, a esse respeito, as análises de Helayel e Brasil Jr. (2019) e Ricupero (2013, p. 527, 532).

${ }^{8}$ Aliás, Helayel e Brasil Jr. (2019, p. 98-99) argumentam que a maneira com que Schwarz se serviu "do debate que estava em curso na Cadeira de Sociologia I da USP na passagem dos anos 1950 para a década seguinte” ocorreu “de modo seletivo e muito próprio”. Nesse particular, os autores ressaltam a relevância que a "crítica de Franco ao diagnóstico de Cardoso a respeito da categoria 'patrimonialismo"” teve em sua análise "do princípio formal da 'volubilidade' de Memórias Póstumas de Brás Cubas (1881)” - exercício iniciado em Ao vencedor, mas arrematado apenas em Um mestre na periferia do capitalismo (ver principalmente p. 105-111). $\mathrm{O}$ artigo também traz importantes considerações sobre os paralelos entre Schwarz e Florestan Fernandes, atento às reflexões de Fernandes a respeito do "patrimonialismo patriarcalismo" na cena brasileira e dos impasses que envolviam a burguesia nacional (p. 111-115).

${ }^{9}$ Para uma reconstrução elucidativa dos caminhos intelectuais de Schwarz e do delineamento de seu objeto de investigação primordial, veja-se Rodrigues (2011, p. 452-506).
} 
Conforme há pouco mencionado, também não faltaram aportes estrangeiros. É Lukács quem "formula o problema da dialética de forma e processo social” (Waizbort, 2002, p. 119), o qual orienta o projeto de Ao vencedor de ponta a ponta. Coube a Trotsky, por sua vez, prover-lhe a chave analítica do “desenvolvimento desigual e combinado", que o auxiliou a destrinchar as divergências entre "a forma machadiana" e o "processo do romance europeu” (Waizbort, 2002, p. 117). Por fim, Auerbach propiciou-lhe parâmetros para abordar o "realismo" em nossa literatura, também rebelde à "regra europeia” (p. 132). Pois bem, apesar de já terem sido tantas vezes destacadas e examinadas pela fortuna crítica, gostaria de revisitar sumária e seletivamente as principais teses do ensaio para, então, contemplar algumas das controvérsias que se lhe seguiram.

"Ao longo de sua reprodução social", assevera Schwarz, "incansavelmente o Brasil põe e repõe ideias europeias, sempre em sentido impróprio.” (Schwarz, 1973, p. 160) Recorde-se que, na percepção do autor, embora o status de país independente houvesse sido alcançado "em nome de ideias francesas, inglesas e americanas, variadamente liberais” (p. 152), a "disparidade entre a sociedade brasileira, escravista, e as ideias do liberalismo europeu” (p. 151) instilava em nossos publicistas e escritores forte sentimento de desconforto. Para Schwarz, não restam dúvidas de que "a liberdade de trabalho, a igualdade perante a lei e, de modo geral, o universalismo eram ideologia na Europa também” (p. 151). No entanto, aqui, as discrepâncias se revelariam mais complexas. Sociedade marcadamente rural, "cuja produção dependia do trabalho escravo" (p. 152), a herança colonial brasileira engendrara nada menos que "três classes de população: o latifundiário, o escravo e o 'homem livre', na verdade, dependente.” (p. 153). Importa sobremaneira ao argumento o fato de que, naquelas circunstâncias, os preceitos mais elevados da "civilização burguesa" - leia-se, "a autonomia da pessoa, a universalidade da lei, a cultura desinteressada, a remuneração objetiva, a ética do trabalho etc.” (p. 154) - não encontravam lastro nas relações entre esses segmentos. Isso porque, coexistindo com a "força" e com a "violência" prevalecentes entre o proprietário de terras e os cativos, o "favor" revelava-se "a nossa mediação quase universal" (p. 154). Vale dizer, tal "mecanismo" articulava-se com as "mais variadas atividades, mais e menos afins dele, como administração, política, indústria, comércio, vida urbana, corte etc.” (p. 153). Daí o liberalismo despontar no Brasil tão somente como 
ideologia "de segundo grau”, incapaz até mesmo de representar "falsamente a realidade" (p. 155).

Note-se que embora "tributários em toda a linha" da Europa, no entendimento de Schwarz, em hipótese alguma constituiríamos mera replicação de seus estágios prévios (Schwarz, 1973, p. 154). Não obstante, seria erro crasso tomar as "ideias" do Velho Mundo por alheias à cena brasileira; afinal, em virtude de sua existência dependente neste "sistema por assim dizer solar, e certamente internacional, que é o capitalismo" (p. 158), era inevitável que as mesmas permanecessem "referência para todos" (p. 151). Ou seja, a despeito de originárias de outras plagas, onde de fato "acompanharam e refletiram transformações imensas na ordem social” ( $p$. 158), tais representações estrangeiras não deixavam de participar "da nossa identidade nacional" (p. 152). De todo modo, , sujeitas "à influência do lugar, sem perderem as pretensões de origem”, acabavam por sofrer uma série de "deslocamentos", donde adviria um "sistema de impropriedades" amplamente "sentido como defeito" (p. 159). No fim das contas, ainda que "fora de centro em relação à exigência que elas mesmas propunham", essas "ideias do tempo" (p. 156) cumpriam papéis e funções locais: além de justificarem o "arbítrio" próprio ao obséquio, outorgavam prestígio àqueles que, ao brandi-las, sentiam-se integrantes duma espécie de "esfera augusta" (p. 154-155).

Mas isso não é tudo. Dentro, ainda, dos horizontes delineados por Schwarz, seria incorrer em novo equívoco interpretar tal "combinação instável” (Schwarz, 1973, p. 155) a contrapelo da "história mundial”, quer dizer, como expressão idiossincrática de uma sociedade apartada no globo. Na verdade, é justamente o contrário que se passaria: lembre-se que, conquanto fôssemos um "país agrário e independente", nossa produção encontrava-se enleada ao "mercado externo" (p. 152), sendo dele dependente. Naquelas circunstâncias, a cadência "de nossa vida ideológica" (p. 158), ou para ser mais exato, o compasso "das conversões e reconversões de liberalismo e favor” constituía “efeito local e opaco de um mecanismo planetário.” (p. 161). Donde a possibilidade de "nossas esquisitices nacionais" possuírem algum “alcance mundial” (p. 159) - o que, de quebra, implicaria conferir-lhes certo potencial de "desprovincianização", de modo que o exame da "originalidade nacional" nos invitaria a "refletir sobre o processo de colonização em seu conjunto, que é internacional.” (p. 161). 
Pois bem, desde sua primeira publicação, os argumentos lançados em Ideias instigaram um conjunto expressivo de debates (Palti, 2014; Ricupero, 2013). Não deixa de ser curioso que uma das primeiras e mais sonoras interlocuções críticas tenha sido lançada justamente por Carvalho Franco (Arantes, 1992, p. 46-50; Ricupero, 2008, p. 61). Com objeções dirigidas inclusive à expressão-chave do ensaio, a autora sugere tratar-se de uma "variante" de certa dualidade "inscrita em pelo menos dois séculos de nossa história intelectual”: aquela pela qual metrópole e colônia, codificadas por meio de "uma ordem de sucessão", acabam retratadas em "uma relação de exterioridade entre os dois termos em oposição" (Franco, 1976, p. 61). O problema maior estaria no fato de a formulação de Schwarz supostamente endossar a existência “de uma diferença essencial entre nações metropolitanas, sede do capitalismo, núcleo hegemônico do sistema, e os povos coloniais, subdesenvolvidos, periféricos e dependentes” (p. 61). Corrigir o tal equívoco requereria apreender tanto estes quanto aquelas como "situações particulares que se determinam no processo interno de diferenciação do sistema capitalista mundial", de cuja essência ambos participariam (p. 62-63). Destarte, tanto “a produção" assim como "a circulação de ideias" deveriam ser percebidas "como internacionalmente determinadas" (p. 62). Por esse motivo, para a autora, naquilo que toca a funcionalidade das "representações igualitárias" no Brasil oitocentista, melhor seria dizer que aquelas ideias estavam bem encaixadas - visto serem "necessárias para sustentar o sistema de dominação e encobrir as disparidades", tanto quanto para "legitimar os desequilíbrios de condição social e a exploração.” (Franco, 1976, p. 63).

Em termos gerais, os alvos dessa polêmica inaugural ressurgiriam de maneira difusa nos debates que então se seguiram. Saliente-se que, na visão de Carlos N. Coutinho (1976, p. 65), na medida em que "o pensamento brasileiro 'importa' uma ideologia europeia”, poder-se-ia inferir “que uma determinada classe ou camada social de nosso país encontrou nessa ideologia a expressão de seus próprios interesses brasileiros de classe.” Com efeito, Alfredo Bosi mostra-se igualmente preocupado com a possibilidade da "filtragem" de ideias adventícias por "grupos sociais" locais em virtude "de seus interesses particulares.” (Bosi, 1995, p. 22) Não por outro motivo, mais relevante que "a origem geográfica de uma dada ideologia", importaria observar a "função que as correntes de pensamento social e político exerceram, de facto, na trama histórica de um dado período.” (p. 22). Ao menos em parte, trata- 
se de uma ponderação compartilhada por Sérgio Rouanet (1994, p. 37), para quem a celeuma em torno das "ideias importadas" seria, a rigor, "uma questão secundária". Além de desconsiderar o choque "entre ideias externas e realidade interna como uma interação verdadeiramente dialética” - com impactos nos dois "polos" da relação (p. 35) -, Schwarz pecaria por devotar pouca atenção à maneira criteriosa e ativa com que "nossa classe dominante”, em circunstâncias específicas, lançou mão do liberalismo, movida "segundo seus interesses particulares” (p. 36). Daí, para Rouanet, o "enorme exagero na tese do desajuste entre ideias externas e realidade brasileira": afora o fato de, em inúmeras ocasiões, terem demonstrado "perfeita congruência" (p. 36), não teriam sido poucas as vezes em que tais "ideais" estrangeiros concorreram "para integrar o Brasil nos grandes circuitos da cultura universal” (p. 37). Dessa feita, além de indevidamente colocada, "a questão das ideias importadas" ocultaria um aspecto bem mais pertinente, qual seja: a "estrutura de poder da sociedade brasileira", em seu entendimento, um problema irredutível ao "topos da autenticidade cultural” (p. 37).

Ponderações análogas voltam a aparecer em Elías Palti (2014, p. 61, 64), com destaque para o suposto de Ideias acerca da "existência de algum tipo de "essência interior”, infensa a representações “"estrangeiras”. Ora, a seu ver, ao fixar "um lugar (...) como o lugar da Verdade", e ao restringir "a linguagem a uma mera dimensão referencial”, Schwarz daria "margem à oposição entre ‘ideias' e 'realidade”". O problema, no entanto, é que a definição de "quais ideias estão ou não fora do lugar" - ou seja, as "atribuições de 'alteridade' a determinadas ideias" - consistiria, para Palti, num empreendimento “com caráter eminentemente político" (p. 62). Daí reivindicar de Schwarz três ajustes em suas formulações: deixar de tratar contextos "centrais" e "periféricos" já de partida "como se fossem entidades fixas e homogêneas" (p. 70); em segundo lugar, em vez de supor a existência de configurações onde ideias e realidades encontram-se organicamente ajustadas e imunes à “contradição", atentar para os "deslocamentos semióticos” decorrentes da "presença, no interior de cada cultura, de uma pluralidade de agentes e modos de apropriação" (p. 70-71). Finalmente, seria preciso considerar minuciosamente "cada contexto discursivo particular" de modo a compreender "como certas ideias ou modelos e não outros acabam aparecendo como 'fora do lugar”, mas também “como algumas ideias ou modelos que em certas circunstâncias apareceram, para certas pessoas, como estando em 
seu lugar apropriado passaram eventualmente a ser vistas, por essas mesmas pessoas como ‘fora do lugar' (e vice-versa)” (p. 72) Por tudo isso, ao invés do “esquema dos 'modelos' e 'desvios”' (p. 74), mais apropriado seria dedicarse a "uma história de linguagens políticas e dos modos de sua articulação, circulação e apropriação social” (p. 73).

\section{A história mundial à luz da periferia: réplicas de Schwarz}

Não foram poucas, pois, as críticas que reclamaram de Roberto Schwarz maior cautela no tocante ao problema das origens, do dinamismo e dos possíveis usos de referências cognitivas, ético-morais e estéticas que balizam a experiência da modernidade no Brasil. Nessa direção, convergindo com Rouanet e Bosi, Ventura (1991) destaca a suposta desatenção do ensaio aos rearranjos que as "ideias" europeias (dentre elas as "teorias racistas" e o "liberalismo") sofreram no Brasil durante o século 19, em decorrência dos "interesses de grupos nacionais identificados à modernidade ocidental" (Ventura, 1991, p. 58-59). Naquelas circunstâncias, afirma Ventura (1991, p. 40), a intelectualidade brasileira selecionou "aquelas que pudessem ser sincretizadas a partir da questão nacional, relacionadas à construção do Estado e à afirmação da identidade das camadas letradas e dirigentes." Nesses mesmos passos, Lília Schwarcz argumenta que não se poderia compreender a "adoção" entre nós das teorias racistas formuladas na Europa oitocentista como "mero reflexo" ou simples “cópia desautorizada" das mesmas. De outro modo, haveria que se "indagar sobre seus novos significados contextuais", "verificar sua relação com a situação social, política, econômica e intelectual vivenciada no país", bem como "atentar para a criação de novos valores e concepções” (Schwarcz, 1993, p. 242). Destarte, o ponto fundamental passaria a ser "pensar na originalidade da cópia” (p. 243), ou se assim se preferir, no "uso original" de "símbolos disponíveis" em situações e “contextos” específicos (p. 242).

Mas, afinal, até onde tais aspectos apontados pela fortuna crítica de fato excedem os horizontes de percepção de Ideias? Na avaliação de Ricupero (2008), não teriam faltado mal-entendidos na recepção de Schwarz. Em sua defesa, o autor sublinha a necessidade de se levar a sério "a particularidade de nossa situação no capitalismo internacional”, para ele um aspecto diluído 
nas críticas desferidas por Maria Sylvia (Ricupero, 2008, p. 61-62). Ao mesmo tempo, Ricupero atenua as ponderações de Bosi e Coutinho, sob a alegação de que a problemática das filtragens de referências europeias reclamada por ambos, algo decorrente dos "interesses das classes presentes na sociedade", poderia sem grandes dificuldades ser conciliada com as propostas originais do ensaio (p. 62). No fim das contas, Ricupero adverte que a preocupação central de Schwarz não seria tanto exprimir a "inadequação de certas referências intelectuais a um dado contexto social”, mas sim tratar de questões próprias a "um processo de formação" que se serve de "formas" oriundas dos "países centrais" - as quais, sob as "condições sociais" específicas do novo lugar, passariam por uma "torção" que as faz "praticamente irreconhecíveis" (Ricupero, 2008, p. 64-65).

Com efeito, o próprio autor não se eximiu de responder a seus críticos. Em "Nacional por subtração" (1986), preocupado com o rendimento analítico da categoria “cópia”, Schwarz volta a indagar se, de fato, a ruptura “conceitual com o primado da origem” seria suficiente para "equacionar ou combater relações de subordinação efetiva” (Schwarz, 1987, p. 36). Não menos estéril parecia-lhe ser "renunciar ao empréstimo para pensar e viver de modo autêntico" (p. 39). Isso porque, a seu ver, "o problema durável e de fundo" (p. 29) permaneceria inalterado, a saber: "a fatalidade da imitação cultural” (p. 36), longe de opção suscetível de descarte, estaria vinculada à posição do país no sistema mundial e à "estrutura econômico-social" altamente desigual consolidada nessas circunstâncias (p. 42). Reafirmando, pois, o enquadramento de Ideias, Schwarz reitera o argumento de que a "má-formação brasileira”, que tanto desconforto trouxe à vida intelectual do país no século 19, não poderia ser explicada isoladamente, mas como parte e parcela da "história contemporânea", ou para ser mais exato, pelas “desarmonias ciclópicas do capitalismo mundial” (p. 45). Segue-se disso um importante aprofundamento no insight de Ideias: refratário à "conotação psicologizante” da categoria “cópia” (p. 36), mas sem pretender dispensá-la integralmente, Schwarz sustenta que em vez de se contrapor "o nacional ao estrangeiro e o original ao importado", mais valeria "ver a parte do estrangeiro no próprio, a parte do imitado no original, e também a parte original no imitado" (p. 48). ${ }^{10}$

\footnotetext{
${ }^{10}$ Esse mesmo aspecto é enfatizado na excelente análise que Lage (2016, p. 55) realiza das proposições de Schwarz. Veja-se, também, as interlocuções de Maia (2009, p. 163-164).
} 
Um mestre na periferia do capitalismo, consumação do projeto anunciado em Ao vencedor, revisitaria novamente o cerne das indagações de Ideias. Em meio ao exame da "segunda fase" de Machado de Assis, o autor retoma, com evidente sinal de reforço, um aspecto basilar do argumento, não raro subapreciado (quando não, de fato, mal interpretado) pela fortuna crítica: a importância analítica a ser dispensada à dinâmica mundial, sem o que não se conseguiria capturar a "diferença de fundo" entre o Brasil e as "nações capitalistas adiantadas" - e, ato contínuo, compreender "a polarização sui generis e desconcertante a que a vida nacional submetia um conjunto de categorias pertencentes à experiência moderna” (Schwarz, 1998, p. 223224). Tratar-se-ia, pois, de asseverar que, longe de "uma aberração brasileira (ou latino-americana)”, o "desenvolvimento moderno do atraso" prendia-se ao “desenvolvimento desigual e combinado do capitalismo”" e à “divisão internacional do trabalho", em virtude do que, às sociedades recémindependentes teria restado tão somente cumprir "o papel de consumidores de manufaturados e fornecedores de produtos tropicais" (1998, p. 38). Sendo esse o caso, não se poderia de modo algum encontrar "a causa última da absurda formação social brasileira” nos limites do próprio país, mas "nos avanços do capital e na ordem planetária criada por eles” (p. 39). Por esse mesmo motivo, admitidas as singularidades da sociedade brasileira do século 19 - trespassada por "questões práticas e ideológico-morais próprias" -, seria também possível, por seu intermédio, indagar sobre "a atualidade mundial”, pelo menos em "alguns de seus segredos” (p. 39).

Verdade seja dita, não faltaram oportunidades em que as réplicas de Schwarz foram explicitamente endereçadas. Para começar, reagindo a Bosi, o autor esclarece jamais ter pretendido "que o liberalismo não tivesse funções no Brasil escravista"; ocorre que o reconhecimento desse fato não bastaria para atenuar o "travo virtual ou efetivo de inadequação", produto da esdrúxula articulação entre "escravidão" e norma liberal (Schwarz, 1999, p. 98-99). Adicionem-se a isso dois outros importantes problemas que Schwarz identifica na "metáfora do filtro": de um lado, o risco de deixar de "explicar por que, apesar de adaptado, o liberalismo e demais instituições modernas tinham conotação absurda no país” e, de outro, o desapreço pelas "condições e antagonismos globais, sem cuja presença as diferenças locais ou nacionais não se entendem” (p. 100-101). Respostas explícitas também foram oferecidas às críticas de Maria Sylvia. Naquilo que toca o alegado "dualismo" de seu enquadramento, Schwarz salienta tratar-se de "um dado 
geral do capitalismo em toda parte", assumido como "ponto de partida" analítico, mas com o intento de apreendê-lo dialeticamente, "dentro de um movimento mais amplo e de fundo" (in Schwarcz \& Botelho, 2008, p. 152153). Nesse caso, o autor reafirma sua intenção de inquirir as articulações entre o "efeito de deslocamento" das "ideias" no Brasil e sua funcionalidade no novo contexto (p. 154). Mesmo assim, pondera que, graças a seu "objeto" - a prosa machadiana -, logrou alcançar algo a mais em comparação com a pesquisa de Carvalho Franco, a saber, indagar sobre o "padrão europeu” a partir da vida local (in Schwarcz e Botelho, 2008, p. 153). ${ }^{11}$

\section{Uma chave de leitura para as interpretações do Brasil}

A respeito das virtualidades inscritas na articulação da "análise estilística com a reflexão histórico-social”, Schwarz remete-se a uma proposição de T. Adorno que ele mesmo assume como um "parti pris metodológico": por meio de "uma análise interna cerrada de uma obra de valor", seria possível desvelar "uma forma de organização que alude de maneira importante à história contemporânea." (in Schwarcz \& Botelho, 2008, p. 150). ${ }^{12}$ Não menos importante, chama-nos atenção para a relevância de J. P. Sartre em sua decisão de dedicar-se a Machado em seu doutorado, àquele momento, por muitos "considerado o menos brasileiro dos escritores brasileiros" - em especial a sugestão sartreana segundo a qual "no andamento do estilo de um bom autor de alguma maneira está presente a história mundial”. ${ }^{13}$ No caso brasileiro, essa agenda de reflexão demonstraria "um interesse suplementar,

\footnotetext{
${ }^{11}$ Como observa Rodrigues (2011, p. 466, 470), “o referente sem o qual, sua [de Schwarz] tese é ininteligível e a apropriação dela, deliberadamente distorcida é o capitalismo mundial”, o que envolve "uma interpretação [tanto] em escala nacional quanto global, assim como o domínio da articulação de ambas”.

${ }^{12}$ Os romances de Machado de Assis, bem sabemos, constituem o foco fundamental desse exercício, concretizado de maneira exemplar em Ao vencedor as batatas e Um mestre na periferia do capitalismo. Sobre a importância de Adorno em seu projeto, veja-se, por exemplo, Schwarz (2012).

${ }^{13}$ É digno de nota que Sartre também figura entre os que influenciaram o delineamento metodológico da tese de doutorado de Fernando H. Cardoso. Na Introdução à obra, ao defender "a utilização do método dialético de forma heurística”, Cardoso (2013, p. 47) remete-se a uma longa passagem de Questão de Método para defender que "totalidades sociais” deveriam ser concebidas "como totalidades singulares". Observe-se que, naquela obra de referência, Sartre (1966, p. 26) sustenta que quando Marx "subordina os fatos anedóticos à totalidade (...) é através deles que quer descobri-la”, atribuindo "a cada acontecimento, além de sua significação particular, um papel de revelador" do "todo". A respeito dessas e de outras afinidades intelectuais, veja-se também Rodrigues (2011, p. 218-230).
} 
que é o da desprovincianização”, por meio da qual seria possível revelar que, além da dimensão "pessoal”, também "a escrita (...) pertence a uma história mais ampla, nacional, e que, no limite, o seu alcance pode ser mundial”. (in Schwarcz \& Botelho, 2008, p. 148). Ademais, como tantas vezes já assinalado pela fortuna crítica (e.g., Melo, 2014; Rodrigues, 2011; Waizbort, 2002), suas interlocuções com Antonio Candido, em particular o anseio de combinar “análise formal e localização sociológica enquanto complementares" - o que envolvia "ler o romance sobre fundo real", ao mesmo tempo que "estudar a realidade sobre fundo de romance, no plano das formas mais que dos conteúdos" -, foram igualmente determinantes para os rumos tomados por sua pesquisa (Schwarz, 1987, p. 130, 140). ${ }^{14}$

Como quero argumentar, parcela importante do que Schwarz reivindica para a análise literária é passível de ser estendida ao campo de investigação dos chamados intérpretes do Brasil: refiro-me à possibilidade de, por meio da inquirição do pensamento brasileiro, desvelar-se aspectos do contexto societário mais amplo - de seus padrões de sociabilidade, das referências ético-morais e estéticas, bem como das categorias de entendimento correspondentes - em que foram engendradas certas imagens do país e da experiência moderna que marcaram época. É certo que, como Candido (1993, p. 11) já havia alertado, "a capacidade que os textos possuem de convencer depende mais da sua organização própria que da referência ao mundo exterior”. Ainda assim, de um modo ou de outro, lá estariam "a sociedade e as circunstâncias históricas", isto é, os "materiais não literários" - leia-se, "natureza, sociedade e ser" -, "manipulados a fim de se tornarem aspectos" da "narrativa ficcional” (Candido, 1993, p. 10, 9). ${ }^{15}$ Ora, a meu ver,

\footnotetext{
${ }^{14}$ Ao rememorar a importância de "Dialética da malandragem” para seu projeto, Schwarz (in Schwarcz \& Botelho, 2008, p. 148) argumenta que Candido iniciou a trilha de investigação que ele acabaria por perseguir, ao buscar "maneiras consistentes de incluir uma obra brasileira na discussão cultural contemporânea mais ampla, ou mundial.” Novamente, não sendo o objetivo central do artigo examinar em seus pormenores as influências intelectuais de Schwarz, precisarei deixar esse aspecto para uma outra ocasião. Seja como for, lembro aqui tanto de "Pressupostos, salvo engano, de 'dialética da malandragem”" quanto de "Adequação nacional e originalidade crítica”, em que as afinidades e alguns dos desacordos com o mestre vêm à tona pelas mãos do próprio autor (Schwarz, 1987, 1999, respectivamente).

${ }^{15}$ Lembre-se que, para Schwarz (1987, p. 141), “a junção de romance e sociedade” ocorreria "através da forma", tomada "como um princípio mediador que organiza em profundidade os dados da ficção e do real”. Apesar das inúmeras convergências entre Candido e Schwarz, certamente não deixaram de existir desencontros. A esse respeito, veja-se a discussão de Melo (2014, p. 404-405 e demais ), em que, contabilizadas as "afinidades metodológicas" em torno da "redução estrutural”, aponta-se para suas "divergências ideológicas", bem como para as diferenças entre "as visões da modernidade brasileira dos dois críticos" e, de maneira mais específica, entre suas percepções do significado da fatura machadiana.
} 
guardadas as especificidades do enquadramento e do método que Schwarz mobiliza para destrinchar os significados da produção machadiana, há aqui uma pista valiosa acerca dos potenciais rendimentos da investigação de formulações-chave desse pensamento: além de possibilitar discernir o que há de irredutível em cada trabalho, a análise meticulosa da fatura e da economia interna das obras permite-nos também alumbrar as circunstâncias sociais e a configuração societária (nacional e extranacional) que as condicionaram. Em igual medida, Ideias e suas interlocuções críticas lançam sugestões promissoras para lidarmos com três aspectos basilares desse universo intelectual: (i) o teor das preocupações e dos objetos de reflexão contemplados por distintas gerações de nossos intérpretes; (ii) os parâmetros de que se serviram em suas tentativas de descrever, compreender e explicar a experiência social brasileira; (iii) as relações (de proximidade e distanciamento) dessas impressões e retratos do país vis-à-vis certo imaginário sociológico da modernidade.

Para começar, é mister reconhecer que, diante da indisfarçável variedade de posições e abordagens que conformam tal constelação de ideias, qualquer tentativa de precisar seus contornos e identificar eventuais pontos de convergência esbarra em um enorme desafio: temas e questões tão numerosos quanto sortidos, gerações e coortes de autores dispersos no tempo e no espaço, além de perspectivas analíticas díspares, não raro excludentes em seus embasamentos epistemológicos mais fundamentais (Botelho, 2010; Botelho \& Schwarcz, 2009; Cardoso, 2013; Lage, 2016; Tavolaro, 2017 ) esses e outros aspectos instigam-nos inevitavelmente a suspeitar da real coesão dessa produção. ${ }^{16}$ Verdade seja dita, guiadas por diferentes critérios, não faltaram tentativas de destilar padrões e de organizar esse quadro intelectual intricado (Brandão, 2007; Liedke, 2005). ${ }^{17}$ Admitidos seus êxitos,

\footnotetext{
${ }^{16}$ Atendo-se aos célebres trabalhos das décadas iniciais do século 20, que se debruçaram sobre “a formação da sociedade brasileira”, Botelho (2010, p. 47-48) aponta para uma ordem análoga de dificuldades: para esse autor, "buscar qualquer unidade para os ensaios de interpretação do Brasil escritos entre 1920 e 1940 constitui, na melhor das hipóteses, um movimento analítico de atribuição e não de inferência de unidade" - algo que, a seu ver, teria se consumado apenas "a posteriori, e em especial pelas ciências sociais”. Parece-lhe, enfim, que tal imputação no mais das vezes subestima "as diferenças significativas existentes entre eles”, dentre as quais percepções discordantes do que seriam as especificidades brasileiras, os pesos conferidos a distintas âncoras explicativas, além da diversidade de circunstâncias socio-históricas em que foram produzidos.
}

17 Aliás, conforme também sublinhado por Botelho (2010 , p. 49-50), tais exercícios iniciaramse já na década de 1950 entre "os pioneiros cientistas sociais profissionais" - dentre os quais, Guerreiros Ramos, Edison Carneiro, Costa Pinto, além de Florestan Fernandes e Antonio Candido. 
permanece, contudo, o desconforto quanto à suposta unidade desse universo complexo e heterogêneo de visões - o que, uma vez mais, nos convida a refletir em que sentido e sob que justificativas poder-se-ia legitimamente atribuir-lhe já de partida qualquer identidade nacional.

Como se viu há pouco, esta é uma preocupação onipresente nas controvérsias que acompanham Ideias: afinal, em que medida poder-se-ia falar de uma "vida ideológica" singular ao país, diversa de outras constelações intelectuais? Caso houvesse concordância acerca das ancoragens nacionais específicas dessa experiência, quiçá boa parte das complicações se diluísse: existindo, em sua essência mais íntima, uma configuração societária peculiarmente brasileira, talvez fosse de se esperar que conceitos, valores, referências estéticas e padrões comportamentais próprios - "ideias", em sentido amplo - florescessem em sua esteira; e que um pensamento igualmente especial ali se projetasse, movido por temas, preocupações, categorias e procedimentos de investigação condizentes com tal existência sui generis. Ocorre que Ideias e seus críticos apresentam uma situação bem mais complexa, refratária a qualquer sorte de imagem autossuficiente da sociedade brasileira. A tomar pelo enquadramento sugerido no transcurso do debate, os aspectos mais decisivos dessa experiência - inclusive os interesses e aspirações dos distintos segmentos sociais - não deveriam ser concebidos como inerentemente seus, tampouco como reflexos de dinâmicas e processos de sua exclusividade. De outro modo, mais apropriado seria tratá-los como desdobramentos da posição, das funções, tanto quanto das possibilidades do Brasil na cena moderna. Somente à luz desses fatores, eles próprios tributários de um sistema global de relações, seria possível compreender a compleição (passada e presente) do país, bem como o sentido de suas transformações; mutatis mutandis, apenas atentos aos imperativos e códigos desse mesmo sistema seríamos capazes de apreender adequadamente o teor dos valores, das visões de mundo, dos padrões cognitivos e das referências ético-morais e estéticas discernidos nessa sociedade. Daí o zelo a ser dispensado ao trânsito das "ideias" modernas e às condições e circunstâncias de sua incidência no Brasil - circunstâncias e condições essas, em larga medida, também condicionadas pelo lugar e pelas funções do país no sistema mundial.

A se considerar essas ponderações, faria ainda algum sentido falar-se de qualquer identidade subjacente aos inúmeros esforços de interpretação do Brasil? Contabilizados uma vez mais os predicados irredutíveis de cada 
obra e abordagem, parece-me haver uma predisposição compartilhada, qual seja, a de assentir acerca de uma dimensão especificamente nacional na vida social brasileira; é justamente às pretensas origens, aos alegados atributos característicos, assim como aos presumidos ordenamentos e transformações dessa dimensão que tais trabalhos devotam atenção prioritária. Trata-se de dizer que - apesar de nem sempre convergirem no tocante às fontes originárias dessa sociedade, aos itinerários de sua formação, ou mesmo aos móveis e sentidos de suas mudanças - perspectivas de análise e gerações de intérpretes as mais variadas tenderam a anuir a respeito da existência de uma vida nacional portadora de traços distintivos, resistentes à passagem do tempo (Maia, 2009, p. 165; Tavolaro, 2014 ; Lage, 2016). O que Ideias e sua fortuna nos ajudam a também perceber é que parcela considerável dessa fatura se inclinou a associar tais feições definidoras aos pretensos descompassos brasileiros vis-à-vis os contextos hegemônicos da modernidade (Schwarz, 1987, p. 30; Arantes, 1992, p. 100; Tavolaro, 2005). Amplamente difuso, não raro codificado como expressão do "atraso" do Brasil (Bastos, 2003, p. 185), tal "sentimento da contradição entre a realidade nacional e o prestígio ideológico dos países que nos servem de modelo” (Schwarz, 1987, p. 30) mostrou-se determinante para seus horizontes de imaginação: em grande medida, a escolha dos temas e questões que se mostraram mais prementes no pensamento brasileiro viu-se condicionada por essa "sensação de defasagem”. Não surpreende, pois, a profusão de trabalhos interessados nas repercussões comportamentais supostamente perniciosas do meio tropical Silvio Romero (1949), Euclides da Cunha (2016) -, de obras ocupadas com os efeitos morais pretensamente funestos da composição étnico-racial do Brasil - Nina Rodrigues (1938), Oliveira Vianna (1956) e Paulo Prado (2012) -, de ensaios ciosos das sequelas institucionais de nossas heranças culturais - Freyre (2000) e Sergio B. Holanda (1994) -, de projetos empenhados em compreender os impactos econômicos profundos - Caio Prado Jr. (2011), Celso Furtado (2009) e Florestan Fernandes (2006) - e as implicações intelectuais pertinazes - Manoel Bomfim (1993) e Guerreiro Ramos (1996) - da condição subsidiária do país, de obras aturdidas com os disparates do quadro político brasileiro - Alberto Torres (1978), Faoro (2001) e Victor N. Leal (2012) -, dentre outros temas e problemas de reflexão - em todos esses casos, é evidente o espectro das "decalagens", "deficiências" e "desacertos" da experiência nacional. 
Conforme há pouco assinalado, articulado a tal problemática, há outro aspecto das interpretações que essa mesma chave de leitura permite elucidar, a saber, os parâmetros acionados com o intuito de desvendar as alegadas peculiaridades, meandros e virtualidades do país. Também aqui, além de abundantes, as divergências entre as visões da realidade inscritas nas obras são por vezes espantosas. Ao longo do tempo, distintas gerações e abordagens valeram-se de um sem número de variáveis, com o amparo das quais delinearam retratos díspares da vida social brasileira: clima, raça, meio físico, dimensão territorial, herança cultural, estrutura econômica, arranjo político-institucional, posição geopolítica, configuração demográfica, dentre outras, conjugadas ou não entre si, constituíram os alicerces de incontáveis tentativas empreendidas com o fito de determinar o que haveria de característico ou mesmo de especial nessa experiência. Ideias e seus críticos auxiliam-nos a perceber que, guardadas as maneiras inconfundíveis com que aferiram essa realidade, predominou certa inclinação convergente: um conjunto bastante seleto de configurações societárias tendeu a ser adotado como padrão de medida nas formulações. Ou seja, malgrado a diversidade das ancoragens explicativas empenhadas, é sobre o pano de fundo de contextos tomados por modelares da modernidade que as mais prestigiadas obras de interpretação do Brasil buscaram identificar os percalços da formação nacional, perscrutar seus atributos distintivos e estimar o escopo de possibilidades do país (Tavolaro, 2005, p. 6, 2014, p. 644 ; Lage, 2016, p. 28). Não surpreende, pois, o teor das visões então esboçadas - no mais das vezes, imagens alusivas a uma vida social descompassada na quadra moderna, perpassada por problemas e conflitos de toda sorte, além de afligida por um futuro incerto. No transcorrer das gerações que conformaram tal pensamento, esses e outros aspectos foram retratados em referência direta às adversidades ditadas pelo meio natural (Euclides da Cunha e Silvio Romero), aos supostos vícios primordiais de nossas gentes (Nina Rodrigues e Oliveira Vianna), às inconstâncias e despreparo de sua cultura ante os imperativos da racionalidade moderna (Buarque de Holanda), às sobrevivências perniciosas de nossas heranças coloniais (Manoel Bomfim), aos inúmeros desafios antepostos à industrialização e à autonomia plena do Brasil (Prado Jr.), às incongruências das instituições que vicejaram em seu seio (Nabuco), às precariedades e inconsistências de sua vida pública (Oliveira Vianna e Faoro), às debilidades políticas decorrentes da dispersão demográfica e 
das dimensões continentais do território (Alberto Torres) etc. Enfim, por diferentes ângulos, avulta a imagem de uma vida social desconexa, aquém dos padrões societários entrevistos em contextos modernos modelares.

Ocorre que, a se considerar esses debates suscitados por Ideias, por mais risíveis que várias dessas formulações pareçam hoje, não se poderia simplesmente tomá-las por manifestações intelectuais idiossincráticas de uma sociedade retardatária. É certo que, na concepção de Schwarz (1999, p. 115), "nos países saídos da colonização, o conjunto de categorias históricas plasmadas pela experiência intraeuropeia passa a funcionar num espaço com travejamento sociológico diferente”. Ainda assim, para o autor, taldiferença de modo algum equivaleria à impertinência dessas noções no novo lugar, visto ambos - a sociedade brasileira e os contextos centrais - situarem-se “[n]um espaço de mesma ordem, (...) comandado pela dinâmica abrangente do capital, cujos desdobramentos lhe dão a regra e definem a pauta.” ( p. 115-116). ${ }^{18}$ Em verdade, a meu ver, essas interlocuções indicam tratar-se de retratos e visões do país alinhados a um dado imaginário da modernidade bastante abrangente e difuso, o qual propende-se a imputar a experiências como a brasileira qualidades inconfundíveis com os cenários modelares. Com sólidas ressonâncias também na produção sociológica, de par com a tendência de postular o pioneirismo histórico e o protagonismo (econômico, político, cultural, intelectual, epistemológico etc.) da Europa, esse ideário inclina-se a conferir um estatuto tardio e reflexo ao Brasil e a configurações congêneres - seja no tocante a seus padrões materiais, seja com relação a seus valores e visões de mundo, às suas referências morais, estéticas e institucionais. Isso posto, como desejo frisar, as proposições de Schwarz e de sua fortuna crítica tocam em ainda outro aspecto fundamental: a despeito

\footnotetext{
${ }^{18}$ Não é minha intenção sugerir que o enquadramento analítico-interpretativo de Schwarz e a linha de investigação que aqui proponho sejam totalmente acordes. Basta memorar que, em sua análise do ensaio de Candido a respeito de O cortiço (de Aluísio Azevedo), Schwarz (1999, p. 35, 52) não dá mostras de renunciar à relevância conferida à alegada "história social particular" do país; tampouco abre mão de estimar "as diferenças que o distinguem das sociedades [europeias] que lhe servem de padrão". Ademais, de modo algum declina da "intuição” do Seminário de Marx, isto é, "articular a peculiaridade sociológica e política do país à história contemporânea do capital, cuja órbita era de outra ordem.” (p. 113. Itálicos meus). Várias das dissonâncias entre Schwarz e minha agenda de investigação podem ser discernidas nas próprias críticas mencionadas ao longo deste artigo. Dito isso, interessa-me explorar as sugestões desses debates para um enquadramento relacional da modernidade, uma ambição que encontra lastro na fatura do próprio autor - "De fato, as fronteiras nacionais são um limite - ou contexto - arbitrário para a vida do espírito moderno. (....) o próprio sentimento do relativo das fronteiras políticas certamente corresponde a uma experiência social efetiva, condicionada por processos de raio mais amplo" (Schwarz, 1999, p. 39-40. Itálicos meus).
} 
de sua aderência aos mencionados supostos hegemônicos, as lucubrações de nossos intérpretes nem sempre permaneceram obedientes a seus termos exatos . Longe disso, em suas tentativas de descrever e explicar uma vida social presumidamente descompassada dos parâmetros da modernidade, não foram poucas as ocasiões em que essa fatura burilou ideias sugestivas de um enquadramento alternativo (Maia, 2009; Maia, 2011, p. 72-73; Lage, 2016, p. 36-38; Tavolaro, 2005, 2017). ${ }^{19}$

\section{Por uma perspectiva relacional da modernidade}

Qual abrangência poder-se-ia franquear às cogitações das/os intérpretes do Brasil? Note-se que, ao se debruçar sobre "as idas e vindas de arbítrio e favor" na obra de Machado de Assis, Roberto Schwarz quer advertirnos justamente para "o alcance mundial que têm e podem ter as nossas esquisitices nacionais.” (Schwarz, 1973, p. 159) Em minha avaliação, tão logo colocada em diálogo com sua fortuna crítica, essa proposição abre um flanco de reflexão igualmente promissor. Refiro-me à possibilidade, também sugerida em diversos momentos desses colóquios, de ao menos alguns elementos dos retratos, visões e diagnósticos delineados por nossos intérpretes ajudarem a elucidar padrões societários, parâmetros estéticos e ético-morais, bem como categorias do entendimento pertinentes não apenas à experiência brasileira e a contextos congêneres, mas também às chamadas configurações modelares da modernidade (Arantes, 1992, p. 100-101; ; Ricupero, 2008, p. 68; Ricupero, 2013, p. 529-530; Maia, 2009, p. 156, p. 162-166; Lage, 2016, p. 45-51; Tavolaro, 2005). ${ }^{20}$ Trata-se, com efeito, de aspectos e facetas em regra subvalorizados, quando não integralmente descartados pela imaginação sociológica, sob o pretexto de serem estranhos ou apenas residuais à sociabilidade moderna (Tavolaro,

\footnotetext{
${ }^{19}$ Com efeito, Maia (2009, p. 156) argumenta que "o pensamento brasileiro pode falar não apenas do Brasil, mas também sobre dilemas modernos globais a partir de um ponto de vista distinto daquele formulado no mundo europeu e anglo-saxão".

${ }^{20}$ Com referência à passagem de Ideias acima destacada, Lage (2016, p. 46-47) considera que Schwarz indica que "As ideias fora do lugar aqui jogam luz sobre as ideias fora do lugar lá; e, o que é mais, a discrepância brasileira ilumina um processo global.” Por isso, seria possível dizer que "[a] interpretação do Brasil traz uma interpretação da modernidade." Rendimento teórico análogo é sugerido em Ricupero (2008, p. 65, p. 68) e Maia (2009). Dito isso, minha inserção no debate anseia algo adicional: ao aprofundar as críticas à chave das peculiaridades societárias (e às implicações epistemológicas desse registro), conforme observei há pouco, almejo sinalizar para uma visada propriamente relacional da experiência moderna (Donati, 2013; Tavolaro, 2021).
} 
2017). Eis, pois, o insight complementar que esse debate oferece: sopesada a especificidade dos temas, questões e problemas enfrentados por nossos pensadores, as redefinições, guinadas e modificações formais observadas na produção intelectual brasileira (Schwarz, 1973, p. 159; Arantes, 1992, p. 92; Ricupero, 2008, p. 65; Palti, 2014, p. 71) permitem alumbrar um conjunto de vivências que, a despeito de inerente à cena contemporânea, permanece subapreciado ou mesmo suprimido do escopo de cognição a seu respeito. Nessa exata direção, as interlocuções em torno de Ideias também nos despertam para o fato de que distintas coortes e gerações de intérpretes do Brasil examinaram modalidades de experiência social que muitas vezes escaparam às perspectivas hegemônicas da modernidade, ou às quais não se conferiu merecido realce - dentre elas, a abrangência restrita de princípios normativos impessoais, a exclusão e a desigualdade abismais que permeiam a paisagem contemporânea, a resiliência de concepções de mundo mágicoreligiosas intrínsecas ao ordenamento moderno, a persistência de arenas púbicas conformadas por interesses e códigos de convivência privados, a justaposição e ineficiência funcional de esferas, âmbitos e códigos sociais variados, ao lado de outros (Tavolaro, 2005, 2014).

Que fique claro: não se trata de ignorar as particularidades dos interesses locais, dos conflitos, problemas e preocupações circunstanciais, muitos dos quais certamente contribuíram para orientar as atenções dessas/es pensadoras/es e para condicionar suas percepções da realidade (Coutinho, 1976; Schwarcz, 1993; Ventura, 1991; Palti, 2014). Todavia, reconhecer o peso de tais condicionantes não equivale a sentenciar qualquer "diferença essencial" entre a sociedade brasileira e as ditas configurações "centrais" (Franco, 1976, p. 61; Rouanet, 1994; Palti, 2014, p. 70). Mutatis mutandis, computadas as assimetrias (econômicas, políticas, simbólicas, culturais, militares etc.) inerentes à cena mundial (Schwarz, 1977, 1987), seria no mínimo precipitado restringir a esta ou àquela categoria de sociedade o alcance cognitivo das imagens delineadas no pensamento brasileiro: isso porque frações expressivas dos alegados disparates do Brasil (e de outras configurações não-modelares) são elas próprias relacionais, leiase, "internas" ao sistema global de que também participam as chamadas sociedades modelares (Franco, 1976, p. 62-63; Schwarz, 1973, 1987, 1998, p. 39); em segundo lugar, porque os “acervos de bens simbólicos”, os “processos cognitivos" e as constelações de ideias que colorem esse sistema de relações 
constituem parte e parcela de um mesmo "patrimônio" civilizacional, ou ainda, de um "circuito mundial de trocas" amplamente compartilhado (Bosi, 1995, p. 18; Rouanet, 1994, p. 38; Maia, 2011, p. 87); por fim, porque apesar do interesse manifesto de intelectuais brasileiras/os (e daquelas/ es atuantes em contextos congêneres) pelo "problema da originalidade ou da especificidade de nossas respectivas culturas" (Bosi, 1995, p. 17), os problemas de que se ocupam não são outros senão "questões da história mundial" (Schwarz, 1973, p. 161). ${ }^{21}$

À guisa de conclusão, deixe-me brevemente indicar ainda outra seara de reflexão suscitada por esses colóquios. Não restam dúvidas de que, a esta altura, boa parte das variáveis explicativas, das proposições e enunciados de muitos de nossos intérpretes caiu no mais profundo descrédito, tão distantes encontram-se das referências e parâmetros cognitivos em voga. Nada disso, porém, inibiu a impressionante expansão de pesquisas e debates a seu respeito (Botelho \& Schwarcz, 2009, p. 11-17). Decerto, incontáveis motivos poderiam ser elencados para tamanho destaque. Não havendo espaço para examiná-los no escopo deste artigo, gostaria ao menos de apresentar uma última conjectura: parece-me que, em alguma medida, o interesse continuado por essa produção advém da percepção de que ela flerta com preocupações de pesquisa deveras atuais. Evidências disso são os paralelos entre alguns desses retratos da vida brasileira e um conjunto de ponderações e críticas recentemente dirigidas às ambições descritivas e prescritivas do imaginário sociológico. ${ }^{22}$ Nesse caso, chamo atenção para três problemáticas interligadas: primeiramente, de ambos os lados, a sensibilidade à dimensão relacional dos itinerários formativos de contextos nacionais enseja reflexões críticas ao "nacionalismo metodológico" que por muito tempo orientou a imaginação sociológica (Chernilo, 2011; Wimmer \& Schiller, 2002; Donati, 2013; Emirbayer, 1997; Arantes, 1992, p. 85; Rouanet, 1994; Maia, 2011, p. 81-89; Lage, 2016, p. 51; Tavolaro, 2014); em segundo lugar, o zelo de nossos intérpretes com as alardeadas incongruências do Brasil na modernidade remetem-nos aos desafios crescentemente lançados

\footnotetext{
${ }^{21}$ Schwarz argumenta que "embora lidando com o modesto tic-tac de nosso dia-a-dia”, segundo ele, "o nosso romancista sempre teve como matéria, que ordena como pode, questões da história mundial” (Schwarz, 1973, p. 161).

${ }^{22}$ Maia (2009) examina, por exemplo, os pontos de convergência entre o pensamento brasileiro e formulações pós- e decoloniais (e.g., Chakrabarty, 2000; Mignolo, 2005). A estas, acrescentaria proposições do programa das modernidades múltiplas (Eisenstadt, 2000) e da modernidade global (Schmidt, 2012).
} 
às aspirações universalistas e uniformizadoras desse imaginário (Eisenstadt, 2000; Chakrabarty, 2000; Schwarz, 1973); por fim, um e outro casos também nos conclamam a atentar para o protagonismo de configurações nãomodelares na cena moderna, em especial a capacidade demonstrada por tais experiências para forjar padrões societários e referências (ético-morais, cognitivas, estéticas, institucionais) alternativos aos hegemônicos (Mignolo, 2005; Hall, 2011; Lage, 2016; Maia, 2009, p. 162-164).

Pois bem, quiçá o cuidado redobrado por esses aspectos possa contribuir para o exercício de "desprovincianização" tão estimado por Roberto Schwarz, leia-se: "inscrever na atualidade internacional, em forma polêmica, muito daquilo que parecia nos afastar dela e nos confinar na irrelevância." (Schwarz, 1998, p. 13).

\section{Referências}

Arantes, Paulo. (1992). Sentimento da dialética na experiência intelectual brasileira. Paz e Terra.

Arruda, Maria A. (2019). Roberto Schwarz e a interpretação crítica do Brasil. Revista do Instituto de Estudos Brasileiros, (74), 27-32.

Bastos, Elide. (2002). Pensamento social da escola sociológica paulista. In S. Miceli (Org.), O que ler na ciência social brasileira: 1970-2002 (pp. 183-230). Sumaré/ANPOCS.

Bomfim, Manoel. (1993). A América Latina: males de origem. Topbooks.

Bosi, Alfredo. (1995). Origem e função das idéias em contextos de formação colonial. In Centro de Estudos Brasileiros/Embaixada do Brasil em Roma (Org.), Pensamento Brasileiro (pp. 17-31). Renso e Rean Mazzone Editori.

Botelho, André. (2010). Passado e futuro das interpretações do país. Tempo Social, 22(1), 47-66. https://doi.org/10.1590/S0103-20702010000100003

Botelho, André, \& Schwarcz, Lília (Org.). (2009). Um enigma chamado Brasil: 29 intérpretes e um país. Cia. das Letras.

Brandão, Gildo. (2007). Linhagens do pensamento político brasileiro. Aderaldo \& Rothschild Editores. 
Candido, Antonio. (1993). Prefácio. In A. Candido, O discurso e a cidade (pp. 9-15). Duas Cidades.

Cardoso, Fernando H. (2013). Pensadores que inventaram o Brasil. Cia. das Letras.

Chakrabarty, Dipesh. (2000). Provincializing Europe: postcolonial thought and historical difference. Princeton University Press.

Coutinho, Carlos N. (1976). Cultura brasileira: um intimismo deslocado, à sombra do poder? Cadernos de Debate, (1), 65-67.

Chernilo, Daniel. (2011). The critique of methodological nationalism: theory and history. Thesis Eleven, 106(1), 98-117.

Cunha, Euclides. (2016). Os Sertões. Ubu Editora.

Donati, Pierpaolo. (2013). Relational sociology and the globalized society. In F. Dépelteau \& C. Powell (Org.), Applying relational sociology: relations, networks, and society (pp. 1-24). Palgrave Macmillan. https://www.doi.org/10.1057/9781137407009_1

Eisenstadt, Shmuel. (2000). Multiple modernities. Daedalus, 129(1), 1-29.

Emirbayer, Mustafa. (1997). Manifesto for a relational sociology. American Journal of Sociology, 103(2), 281-317. https://doi.org/10.1086/231209

Faoro, Raymundo. (2001). Os donos do poder. Editora Globo.

Fernandes, Florestan. (2006). A revolução burguesa no Brasil. Editora Globo.

Franco, Maria Sylvia C. (1976). As idéias estão no lugar. Cadernos de Debate, (1), 61-64.

Freyre, Gilberto. (2000). Casa-grande \& senzala. Record.

Furtado, Celso. (2009). Formação econômica do Brasil. Cia. das Letras.

Guerreiro Ramos, Alberto. (1996). A redução sociológica. Editora UFRJ.

Hall, Stuart. (2011). Da Diáspora. Editora UFMG .

Helayel, Karim, \& Brasil Jr., Antônio. (2019). Roberto Schwarz e a sociologia paulista dos anos 1960. Revista do Instituto de Estudos Brasileiros, (74), 97-118.

Holanda, Sérgio B. (1994). Raízes do Brasil. José Olympio Editora.

Lage, Victor. (2016). Interpretations of Brazil, contemporary (de)formations [Tese de Doutorado, Pontifícia Universidade Católica do Rio de Janeiro]. https://doi.org/10.17771/PUCRio.acad.27613 
Leal, Victor N. (2012). Coronelismo, enxada e voto: o município e o regime representativo no Brasil. Cia. das Letras.

Liedke,Enno.(2005).ASociologianoBrasil:história, teoriasedesafios.Sociologias, 7(14), 376-437. https://doi.org/10.1590/S1517-45222005000200014

Maia, João. (2011). Ao sul da teoria: a atualidade teórica do pensamento social brasileiro. Sociedade e Estado, 26(2), 71-94. https://doi.org/10.1590/ $\underline{\text { S0102-69922011000200005 }}$

Maia, João. (2009). Pensamento brasileiro e Teoria Social: notas para uma agenda de pesquisa. Revista Brasileira de Ciências Sociais, 24(71), 155-168. https://doi.org/10.1590/S0102-69092009000300011

Melo, Alfredo C. B. (2014). Pressupostos, salvo engano, de uma divergência silenciosa: Antonio Candido, Roberto Schwarz e a modernidade brasileira. Alea, 16(2), 403-420.

Mignolo, Walter. (2005). The idea of Latin America. Blackwell.

Nina Rodrigues, Raimundo. (1938). As raças humanas e a responsabilidade penal no Brasil. Editora Nacional.

Palti, Elías. (2014). O problema de "As ideias fora do lugar" revisitado: para além da "história das ideias na América Latina". In J. M. Maia et al. (Org.), Ateliê do pensamento social: ideias em perspectiva global (pp. 57-84). Editora FGV.

Prado Jr., Caio. (2011). Formação do Brasil contemporâneo. Cia. das Letras.

Prado, Paulo. (2012). Retrato do Brasil. Cia. das Letras.

Ricupero, Bernardo. (2008). Da formação à forma. Ainda as "idéias fora do lugar". Lua Nova, (73), 59-69. https://doi.org/10.1590/S0102$\underline{64452008000100003}$

Ricupero, Bernardo. (2013). O lugar das ideias: Roberto Schwarz e seus críticos. Sociologia \& Antropologia, 3(6), 526-556. https://doi. org/10.1590/2238-38752013v368

Rodrigues, Lidiane. (2019). Leituras, leitores e lugares de Roberto Schwarz: nota de organizadora. Revista do Instituto de Estudos Brasileiros, (74), 17-26.

Rodrigues, Lidiane. (2011). Anatomia de tese: capitalismo, escravidão e marxismo em São Paulo; 811/2 de Roberto. In R. Rodrigues, A produção social do marxismo universitário em São Paulo: mestres, discípulos e "um seminário" (1958-1978) [Tese de doutorado, Universidade de São Paulo, pp. 210-254, pp. 452-506]. https://doi.org/10.11606/T.8.2012. $\underline{\text { tde-05072012-164401 }}$ 
Romero, Silvio. (1949). História da Literatura Brasileira (Tomo Primeiro). Livraria José Olympio.

Rouanet, Sérgio. (1994). Idéias importadas: um falso problema? Cadernos do IPRI, (15), 31-40.

Sartre, Jean-Paul. (1966). Marxismo e existencialismo. In J-P. Sartre, Questão de Método (pp. 9-33). Difusão Européia do Livro.

Schmidt, Volker. (2012). Conceptualizing global modernity. A tentative sketcth [Working Paper Series, National University of Singapore, pp. 1-52].

Schwarcz, Lilia. (1993). O espetáculo das raças: cientistas, instituições e questão racial no Brasil - 1870-1930. Cia das Letras.

Schwarcz, Lília, \& Botelho, André. (2008). "Ao vencedor as batatas” 30 anos depois: crítica da cultura e processo social. Entrevista com Roberto Schwarz. Revista Brasileira de Ciências Sociais, 23(67), 147-160. https://doi.org/10.1590/S0102-69092008000200011

Schwarz, Roberto. (2012). Sobre Adorno (Entrevista). In R. Schwarz, Martinha versus Lucrécia: ensaios e entrevistas. Cia. das Letras.

Schwarz, Roberto. (1999). Sequências brasileiras. Cia. das Letras.

Schwarz, Roberto. (1998). Um mestre na periferia do capitalismo: Machado de Assis. Duas Cidades.

Schwarz, Roberto. (1987). Que horas são? Ensaios. Cia. das Letras.

Schwarz, Roberto. (1977). Ao vencedor as batatas. Duas Cidades.

Schwarz, Roberto. (1973). Idéias fora do lugar. Estudos CEBRAP, 5, 151-161.

Tavolaro, Sergio B. F. (2021). Imagens contra-hegemônicas da modernidade: uma visada sociológica relacional. In F. Dépelteau \& F. Vandenberghe (Org.), Sociologia Relacional (pp. 267-301). Ateliê das Humanidades Editorial.

Tavolaro, Sergio B. F. (2017). Retratos não-modelares da modernidade: hegemonia e contra-hegemonia no pensamento brasileiro. Civitas, 17(3), 115-141. https://doi.org/10.15448/1984-7289.2017.3.26580

Tavolaro, Sergio B. F. (2014). A tese da singularidade brasileira revisitada: desafios teóricos contemporâneos. Dados: Revista de Ciências Sociais, 57(3), 633-673. https://doi.org/10.1590/00115258201420

Tavolaro, Sergio B. F. (2005). Existe uma modernidade brasileira? Reflexões em torno de um dilema sociológico brasileiro. Revista Brasileira de Ciências Sociais, 20(59), 5-22. https://doi.org/10.1590/S0102-69092005000300001 
Torres, Alberto. (1978). O problema nacional: introdução a um programa de organização nacional. Companhia Editora Nacional/MEC.

Ventura, Roberto. (1991). Estilo tropical: história cultural e polêmicas literárias no Brasil, 1870-1914. Cia. das Letras.

Vianna, Oliveira. (1956). Evolução do Povo Brasileiro. Livraria José Olympio Editora.

Waizbort, Leopoldo. (2002). Influências e invenção na sociologia brasileira (Desiguais porém combinados). In S. Miceli (Org.), O que ler na ciência social brasileira (pp. 85-174). Anpocs.

Wimmer, Andreas, \& Schiller, Nina. (2002). Methodological nationalism and beyond: nation-state building, migration and the social sciences. Global Networks, 2(4), 301-334. https://doi.org/10.1111/1471-0374.00043

\section{(cc) $\mathrm{EY}$}

Licenciado sob uma Licença Creative Commons Attribution 4.0 